\title{
The Utility of Plumage Coloration for Taxonomic and Ecological Studies
}

\author{
Eben H. Paxton* \\ U. S. Geological Survey Southwest Biological Science Center, Box 5614, Flagstaff, AZ 86011, USA
}

\begin{abstract}
Plumage coloration in birds serve multiple purposes, including species recognition, sexual selection cues, and camouflage. Differences in plumage coloration can be used to infer evolutionary relationships, identify distinct taxonomic units, and characterize geographic variation. With the advent of electronic devices to quantify plumage coloration quickly and reliably, taxonomic or geographic differences can be exploited for ecological studies. To evaluate the utility of plumage coloration for taxonomic and ecological studies, I review the basis of plumage coloration and sources of variation. I then review how different studies have used plumage coloration to better understand taxonomic relationships and provide insights into ecological problems.
\end{abstract}

\section{INTRODUCTION}

Human interest in the coloration of bird plumage has a long history, from aesthetic pleasure in the colors, to the importance of plumage coloration in identifying species, to the post-Darwin interest in colorful plumages of many male birds as they relate to sexual selection. Fascination with plumage coloration stems from the rich variety of colors and patterns observed across bird species. Plumage coloration serves a wide range of functions in birds, including species recognition, inter- and intra-sexual signaling, and camouflage. However, plumage coloration has received the most scientific attention for the purpose of grouping taxa, from early efforts to catalog species, to more recent efforts to understand evolutionary relationships. Plumage coloration is believed to help facilitate species recognition, restricting interspecies gene flow, and thus has high taxonomic value [1]. Additionally, plumage coloration is believed to be able to evolve rapidly [2,3], allowing for fine scale taxonomic resolution. For this reason, many original species and subspecies descriptions relied heavily on coloration to separate groups.

However, with the advent of molecular genetic techniques to infer taxonomic relationships, the use of plumage coloration and other morphological traits for taxonomy has diminished $[4,5]$. The reasons for the shift are many. First, the use of genetic markers, particularly neutral markers, is generally believed to provide a more accurate reflection of evolutionary relationships, less likely to be biased by directional selection or confused by convergent evolution [6]. Second, molecular genetic markers are quantitative rather than qualitative, and results can be rigorously tested and in most cases reliably replicated by other researchers. Third, the selection of different molecular markers that change at

*Address correspondence to this author at the U. S. Geological Survey Southwest Biological Science Center, Box 5614, Flagstaff, AZ 86011, USA;

E-mail: Eben.Paxton@nau.edu different rates allows taxonomists to choose molecular marker most appropriate for the level of taxonomic resolution they are examining [4].

Additionally, reliance on phenotypic characters, such as plumage coloration, for the reconstruction of avian phylogenies has been questioned in recent years due to conflicting taxonomic groupings derived from morphology-based versus molecular-based approaches [7]. This has been particularly evident at the intraspecific taxonomic level where morphological and genetic differences can be small. For example, in a study of the geographically widespread Winter Wren (Troglodytes troglodytes), traditional taxonomic groups originally identified based on morphological characters did not always agree with those identified genetically, and in some cases molecular markers revealed genetically distinct groups not apparent from morphological characters alone [8]. In some cases, disagreement between molecular and morphological groupings is due to fundamental differences in how taxa are defined. Many taxonomists have adopted the Evolutionary Significant Unit (ESU)[9] as a phylogenetic classification of subspecies, although adoption of that definition is not universal [10]. An ESU is defined as an intraspecific group which is distinguishable from all other intraspecific groups based on fixed differences between mitochondrial DNA (reciprocally monophyletic) and significant frequency differences in nuclear DNA. Morphology-based definitions of subspecies have varied, but generally attempt to group morphologically similar individuals together, using techniques such as the "75\% rule", where $75 \%$ of individuals from one population should only overlap with $3 \%$ from another population [11]. Comparing the two taxonomic approaches, Zink [7] found that 97\% of morphological subspecies would not be supported by the ESU definition. This debate about how best to define avian subspecies has called into question the many morphologically-based subspecies designations, creating legislative and management challenges especially in cases where threatened or endangered subspecies are concerned [12]. 
One criticism of the use of morphological traits, particularly plumage coloration, in taxonomic designations has been its qualitative nature, inability to be statistically evaluated, and difficulty in replication. With the recent advent of sophisticated electronic tools to quantify color, however, it is now possible to more rigorously and reliably define plumage coloration differences. This has led to a renewal of interest in the use of plumage coloration as an informative trait for recognizing avian species and subspecies $[13,14]$. In particular, studies have begun to incorporate measurements of coloration with genetic studies as an additional informative trait. Perhaps most importantly, quantifying differences in plumage coloration among morphologically similar species and subspecies can be exploited to identify taxonomic groups rapidly in the field, without the additional cost in time and materials required of genetic testing. However, to fully evaluate the utility of plumage coloration in taxonomic studies requires an understanding of the sources of variation in plumage coloration and the degree to which plumage coloration is genetically derived, or influenced by the environment.

\section{NATURE OF AVIAN PLUMAGE COLORATION}

Coloration of avian plumage is derived from pigments, structural properties of feathers, or a combination of the two. For most avian taxa, pigments are the most important contributors to plumage coloration [15]. However, structural characteristics of feathers that impart color are found in a wide range of birds, and are often combined with pigments to enhance pigment-based colors, or create additional colors. For example, the green plumage coloration of many parrot species is a result of yellow coloration from psittacofulvin pigments and a blue reflectance derived from the feather structure, which combine to create the green color that we perceive [16]. The recent renewed interest in feather coloration, combined with advances in technologies for identifying those sources, has led to new discoveries of color sources and the promise of discoveries of other color sources in future years [17].

The most common avian plumage pigment is melanin. Melanin is responsible for many of the blacks, grays, browns and other earth-tone colors seen in avian plumage. In particular, melanin is responsible for all the spotting, striping, and high-contrast patterning typically observed in a wide variety of birds, from owls to waterfowl to passerines [18]. There are two classes of melanin, eumelanins which give rise to black and dark brown hues, and phaeomelanins, which are characterized by a reddish-brown color. However, melanin coloration is typically a mixture of the two types, with the ratio of the two melanins producing the wide variety of colors expressed. Melanin is manufactured by the cell and its expression in feathers is not believed to be strongly influenced by environmental conditions; however, studies are showing variation in melanin due specifically to the availability of essential amino acids [18] or minerals [19], and more generally diet and condition [20,21]. While there may be minor modifications of melanin coloration due to environmental variation, evidence to date suggests that such influences are weak and melanin-based colors generally should be a good reflection of a bird's genotype.

Carotenoid pigments, unlike all other known pigments in birds, are not synthesized by the avian body and must be acquired from a bird's diet. Nonetheless, they are found in a wide range of organisms and are the second most common pigment found in bird plumage [15]. Carotenoid pigments produce the often bright plumage coloration ranging from reds to oranges to yellows, and produce more broad-brush shading and coloration, rather than the distinct patterning often typical of melanin coloration. Carotenoids are a diverse class of light-absorbing molecules, each absorbing light at slightly different wavelengths, and the reflected color is due to the type of carotenoid or combination of different types present in the feather [22]. Because the hue and intensity of color in part reflects the quality of diet (at least the quantity of carotenoids in the diet, but see [23, 24]), carotenoidderived plumage coloration can communicate habitat quality, foraging efficiency, and individual health to conspecifics, and there has been considerable interest in their role as honest-signals of fitness within the framework of sexual selection [25]. However, because of this environmental variation, measurements of carotenoid colors for the reconstruction of phylogenetic relationships should be approached carefully, with full appreciation of the important role of environment in the expression of these pigments across and within populations.

Other classes of pigments, though typically uncommon or taxon-specific, allow for alternative avenues of color expression. These uncommon pigments include porphyrin pigments, which provide reddish-brown plumage coloration in a few avian orders (such as bustards, nighthawks, owls, and turacos); psittacofulvin pigments, found only in parrots, producing red, orange, and yellow coloration; and pterin pigments, believed to be only in the iris of certain birds (such as blackbirds, starlings, and pigeons), but possibly providing yellow in the feathers of penguins [17]. These classes of pigments are derived from different biochemical pathways and much is still unknown about their properties and origin [26]. With new techniques to evaluate the sources of coloration (e.g., liquid chromatography), more birds will be evaluated, and additional pigments likely identified, although novel pigments will most likely continue to be uncommon and taxa specific [17]. Of the rare pigments identified to date, all are apparently created within the body.

Structural colors are derived from nano-scale structures that diffuse or reflect light in specific ways. This differs from pigment-based coloration that is derived from the absorbance and emission of light from a pigment molecule. Structural colors are produced from the interaction of light waves scattering across the interface of materials with different physical refraction properties [27]. The exact color comes from the structure of the material and their refractive properties, and is most pronounced when light moves through layers of materials that differentially refract light to create specific colors, iridescent shine, or UV reflectance [28]. Often structural colors are combined with pigment-based colors, either to reinforce a single color, or to create a new color (such as the case of the green coloration in parrots), and in some case structural coloration can be masked by pigment-based coloration [29]. In particular, UV reflectance, which is invisible to the human eye and has received considerable interest recently [30], is a structurally based color. While variation in structural coloration appears to faithfully reflect genetic variation [31], condition of individuals has been shown to modify UV coloration $[32,33]$. 


\section{SOURCES OF VARIATION IN PLUMAGE COLORA- TION}

\section{Genetics}

Overall plumage coloration is believed to have a genetic basis. While there is evidence of condition-dependent variation in coloration, particularly for carotenoid-based pigmentation, these environmental variations influence degrees of color expression, not the location, pattern, or particular colors expressed. In this sense, plumage coloration could be a valuable character for inferences about taxonomic relationships.

Despite the intense interest in avian plumage coloration, the genetic basis for plumage coloration is poorly understood $[34,35]$. What evidence there is suggests multiple sources for genetic control of coloration, from single-locus to polygenic effects, and different genes presumably control different types of pigment coloration and structural coloration. A number of studies, primarily conducted on domestic and cage birds, have demonstrated simple Mendelian patterns of inheritance [34]. However, the molecular basis for genetic effects has been documented for only one gene [3]. The gene, MC1R, plays an important role in the expression of melanins in many vertebrates, where a single point mutation produces dark (melanin-rich) or light (melanin-poor) plumage morphs depending on which of the two alleles are expressed. This mechanism has been demonstrated as the basis for plumage polymorphisms in several species such as the Snow Goose (Anser caerulescens), Parasitic Jaeger (Stercorarius parasiticus), and Bananquit (Coereba flaveola) $[36,37]$. The two alleles of this gene can be maintained within a species either as a stable polymorphism within a population, as in the case of Snow Geese [38], or can exist as fixed differences between subspecies, as in the case of the White-winged Fairy-wren (Malurus leucopterus) [39]. In contrast, polygenic control of plumage coloration has been indicated in studies of hybrids from cross-fostering studies of domestic birds [40], which suggest that many genes influence different colors within different regions of a bird's plumage. One well studied example in the wild of the genetic basis of color variation is within hybrid zones between Hermit Warblers (Dendroica occidentalis) and Townsend's Warblers (D. townsendii). Of eight color characteristics measured within the hybrid zone, seven showed a continuous cline of variation across the hybrid zone, suggesting polygenic inheritance, while one trait showed an abrupt change, suggesting a single-locus control [41].

\section{Diet and Condition}

While the underlying basis for plumage coloration is derived from genes, condition of birds can influence the expression of color. This is particularly true for carotenoids, which are entirely acquired from the diet. It has long been observed that captive birds without access to a carotenoidrich diet eventually lose the intensity of their carotenoidbased plumage coloration [42]. This diet-deficient loss of color can occur rapidly in soft-tissues, but color change in feathers can only occur during the period of active molt, when the feathers are being grown, because between molts feather color can only be altered through wear, fading, or the addition of external pigments (see below). Because carotenoids are found in many forms, and some forms need to be converted to be used by feathers, different sources of carotenoids may be utilized at different efficiencies within individuals and between species. Studies of American Goldfinch (Carduelis tristis), Northern Cardinal (Cardinalis cardinalis), and House Finch (Carpodacus mexicanus) showed that the response to change in diet varied significantly among the species [43]. In addition, Hill [44] showed that captive individuals provided with food containing a diverse array of carotenoids showed high variability in carotenoid expression, and a similar relationship was documented in wild birds where a positive relationship was found between the carotenoids obtained from sampling stomach contents and the coloration of House Finch's red plumage during molt [45]. However, it is still unclear to what degree the acquisition of carotenoids versus other environmental interactions influences the final expression of color [46]. For example, both natural [23] and controlled experiments [24] suggest that environmental variation consists of more than just the acquisition of the pigments. In a meta-analysis of many different studies, Olson and Owens [47] concluded that the link between diet and carotenoid plumage coloration was important, but the degree of connection varied phylogenetically and on the type of coloration (red versus yellow).

Besides carotenoid-based colors, condition-dependent changes in coloration are believed to be relatively minor, although a number of studies have demonstrated some degree of environmental variation. The expression of coloration involves a number of steps, and there are points within the process where environmental conditions could affect expression of coloration. Melanins are complex molecules synthesized from simpler amino acids and the lack of those amino acids or other elements crucial for the synthesis pathway could disrupt production of melanin. For example, lack of dietary lysine has been linked to diminished melanin in feathers of domestic birds [18]. In addition, calcium, as well as other minerals, helps to facilitate the formation of melanin [48], and thus a diet deficient in these minerals could influence the expression of melanin as was found for Barn Owls (Tyto alba) [19]. Further research on the actual variation of these minerals and amino acids in the diet of wild bird populations is needed to understand the importance of this potential source of environmental variation in melatonin production [48]. Studies have shown that psittacofulvin pigments can vary with environmental conditions that directly effect individuals (drought conditions) [29], and individual condition can influence UV coloration [32, 33]. Nonetheless, it is generally believed that the expressions of non-carotenoid coloration are a relatively accurate reflection of a bird's genetic code [3].

\section{Other Environmental Influences}

Environment can influence plumage coloration after feathers are grown and are generally inert. Examples include waterfowl, where plumage can adopt a reddish hue from iron-rich waters, Bearded Vultures (Gypaetus barbatus) that in some parts of their range will deliberately color their plumage with iron-rich mud, Male Rock Ptarmagin (Lagopus mutus) which will soil their plumage during the period between snow melt and summer molt to reduce the conspicuousness of their white winter plumage, and male Great Hornbills (Buceros bicornis) that apply a yellow secretion from their uropygial gland to color their bill, casque, and 
white feathers of their plumage [49]. In addition to cosmetic coloration, the color of feathers can change over time due to physical abrasion of the keratin structure and UV bleaching of pigments. Several studies have documented seasonal changes in the coloration of birds, including a study of Blue Tits (Parus caeruleus) where UV coloration declined in lightness, though not chroma and hue [50], and in a study of the Great Tit (Parus major) where researchers found that seasonal variation in plumage coloration changed for carotenoid-based plumage pigments, but not for melanin-based plumage coloration [51]. While the changes in feathers due to wear generally reduce color intensity, in some species the overall plumage appears brighter as feathers wear. In one example, the Lawrence's Goldfinch (Carduelis nivalis) molts once a year in the fall, producing a fresh plumage with a grayish/olive tint due to the light unpigmented distal ends of feather barbs; as the feather tips wear throughout the winter, the proximal sections of the feather barbs that contain bright yellow carotenoids are exposed, yielding the bright nuptial plumage characteristic of birds during the breeding season [52]. Originally, it was believed that the yellow, breeding season plumage resulted from a separate molt. Thus, attention needs to be paid to the possibility of feathers gradually changing between molt periods, and such information incorporated into the quantification of coloration.

Ultimately, to understand the degree of variation in plumage coloration that can be attributed to genetic variation versus environmental variation requires an understanding of the basis for the plumage coloration and an understanding of the underlying mechanism(s) of color change through time. While it appears that non-carotenoid coloration is primarily influenced by genetic variability [3], studies have shown that all expressions of color can be potentially influenced by the environment. Effects of seasonal wear on feathers in live birds can be corrected for, as was done in a study of the Blue Tit [53], and the slow fading of plumage coloration in museum specimens compared to live birds can also be corrected for [54]. Even variation in carotenoid colors may have limits on their condition-based variation; understanding the magnitude of variation may allow for careful use of the color for taxonomic purposes. For example, a wide range of red to yellow carotenoid-based coloration is observed among individual male House Finches within a single population. Inouye et al. [55] documented that a significant amount of this variation could be explained when individuals were grouped by age and subspecies, with each age group displaying a different range of colors, and that this range varied between subspecies. They hypothesized that differences in the range of color variation among those groups was a result of how they metabolized or expressed the carotenoid pigments, suggesting a genetic constraint to the degree of variation. Thus, with an understanding of the source of the colors measured, an appreciation of how they may be influenced by the environment, and an effort to capture the full range of variation present in the taxa of interest, plumage coloration can be an informative taxonomic character.

\section{MEASURING PLUMAGE COLORATION}

Color perception is the interaction of ambient light, the reflectance properties of the keratin structure and pigments in the feathers and receiver sensitivity. The avian eye is substantially different than the human eye, with a larger light detection range (315-700 $\mathrm{nm}$ versus $\sim 400-700 \mathrm{~nm}$ in humans) allowing birds to detect wavelengths in the ultraviolet range $[56,57]$. Structurally, avian eyes are tetrachromatic, having four different light-sensing cones, versus the three cone trichromatic vision of humans [58]. These differences in visual perception, and the inability of the human eye to detect colors perceived by birds, may in part explain the disagreement between traditional morphological groupings and genetic analyses.

The use of electronic devices to quantitatively measure color allows for the use of plumage coloration as a taxonomically informative trait independent of the perceptual limits of the human eye. Taxonomists traditionally tried to minimize subjective assessment of plumage coloration by comparing museum specimens with vouchers specimens under the same lighting conditions, or using color charts to better quantify colors [59]. In contrast, electronic devices use a self-contained light to standardize ambient light and make precise measurements of the reflected light. With both ambient light and receiver sensitivity controlled, theoretically the only variance among measurements should be variation in the plumage reflectance properties. Additionally, the quantitative output of values allows for detailed statistical analysis [14].

There are two classes of electronic devices, those designed to mimic the human eye, and those that measure light reflectance across a specified range of light frequency. Devices that measure color within the range of human vision, colorimeters, are designed to provide a specific colorspace value (such as the three-number coordinate for RBG color space commonly used in software programs). In general, they produce values for chroma, which is a measure of saturation or the vividness of a color; hue, which is the actual location of the color in a color spectrum (red, blue, yellow); and lightness, which measures how bright or dark a color is. These three measurements of a color ultimately produce the location of an object's color in a 3-dimensional colorspace. The advantages of these machines are that they provide a single set of numbers that represent a specific color and can easily be analyzed with statistical models. Their disadvantages are that they cannot detect wavelengths outside the range of human eyes (i.e., $400-700 \mathrm{~nm}$ ).

The other class of devices, spectrometers, measure the intensity of reflected light across a broad spectrum (typically 300-700 $\mathrm{nm}$ ), and thus produce a 2-dimensional measurement of color (wavelength by intensity). These devices are superior to colorimeters in that they record the intensity of reflection across a broad spectrum and do not constrain the reflected light to a homo-centric color space. However, exactly how to analyze the continuous, 2-dimensional information presents challenges and is the focus of ongoing research [60]. Regardless of which machine is used, both provide quantitative measurements of plumage coloration that can be replicated, although spectrometers should be used to detect UV-range color.

\section{AVIAN PLUMAGE COLORATION FOR TAXO- NOMIC AND ECOLOGICAL STUDIES}

With the ability to quantify plumage coloration, and a growing understanding of the sources of variation underlying such color, there is a renewed interest in the utility of colora- 
tion as an informative taxonomic trait, especially when coloration is included as one of several traits considered [61]. The number of such studies is still small and the approaches taken by researchers have varied. One approach taken by Patten and Unitt [14] was to use a colorimeter to measure plumage coloration of Sage Sparrow (Amphispiza belli) subspecies, and analyze those measurements with a multivariate statistical version of the old taxonomic " $75 \%$ rule" [11]. As they point out, having a standardized, statistical method (which is only possible with the quantification of color) not only allows the analysis to be repeatable, but also allows the researcher to set different thresholds of confidence for distinguishing subspecies. In addition, it allows for coloration to be treated as a quantitative trait that can be analyzed along with other features, such as morphometric measurements. Another approach is to evaluate original classifications with a more rigorous, quantitative approach. In a study of morphometrics, protein electrophoresis, and subjective evaluation of plumage coloration of Least Tern (Sterna antillarum) subspecies, Thompson et al. [62] concluded that the subspecies were not distinct from one another. In response, Johnson et al. [13] revisited the question based on coloration quantified from a colorimeter, finding statistical differences among plumage coloration and concluded that there was evidence for subspecies status. Johnson et al. [13] argued that because the original trinomial designation was based primarily on plumage coloration, the qualitative approach that Thompson et al. [62] used to evaluate color was insufficient to discriminate among subtle differences in color, but which an electronic device could distinguish. Likewise, a study of two subspecies of the Kerguelen Tern (Sterna virgata) also used an electronic device to distinguish color variation among subspecies to reanalyze the original findings in a more statistically rigorous manner [63].

The use of color devices has also helped in resolving difficult taxonomic issues. For example, measurements from a colorimeter have aided in the description of cryptic species and subspecies in the Neotropics, where high numbers of closely related species coexist. Using coloration measurements and song, Johnson and Jones [64] identified a new species of tody-tyrant in Peru, largely based on $100 \%$ discrimination of the new species from its sister species using differences in plumage coloration. Similarly, Isler et al. [65] utilized information from a colorimeter, vocalizations, and morphometrics to identify a new cryptic species and an additional subspecies within the widespread Amazonian antbird, the Chestnut-tailed Antbird (Myrmeciza hemimelaena). Another example is in the long-running debate on whether McKay's Buntings (Plectrophenax hyperboreus) is a distinct species, or a subspecies, of the Snow Bunting (Plectrophenax nivalis). Maley and Winker [66] used a spectrometer to measure plumage coloration in juveniles of the McKay's Bunting and two separate subspecies of the Snow Bunting. Using quantitative measures of plumage coloration, they found no statistical difference among the two Snow Bunting subspecies, but strong differences between those two and the McKay's Bunting, supporting the view that McKay's Bunting represents a distinct taxon.

Plumage color measurements can also be compared to molecular genetic patterns to better understand taxonomic relationships. Taxonomists have increasingly used multiple molecular markers to better understand evolutionary relationships, and additionally have begun to incorporate non-molecular markers into their analysis. This increased use of multiple informative traits is an acknowledgement that to some degree each marker has its own history, and the consensus history of multiple markers more closely reflects the evolutionary history of the taxonomic group of interest. In some cases the combination of traits can be used to strengthen a conclusion, as was the case in Zink et al. [67] where the combined evidence of molecular genetic structuring and distinct morphological differences, including plumage coloration, was used to argue for species status of two subspecies of the Curve-billed Thrasher (Toxostoma curvirostre). Alternatively, contrasting patterns between morphology and genetics can provide interesting insights into evolutionary history. For example, Zink et al. [2] documented that island populations of the Savannah Sparrow (Passerculus sandwichensis) were distinguishable from mainland populations by plumage coloration, but the island populations were genetically similar to the mainland populations. They used the contrasting results to infer recent colonization of the islands and rapid morphological change. In the Bluethroat (Luscinia svecica), a widespread, polytypic species distributed across Europe, Johnsen et al. [68] used molecular markers to assess phylogenetic relationships among multiple subspecies, augmenting these data with spectrometer measurements of plumage coloration. They found concordance between genetic structuring and color differences in most subspecies, but not all, yet a poor relationship between overall genetic distance among subspecies and absolute differences in coloration values. They used the patterns of the two sets of informative traits to reconstruct a complex evolutionary history of the species in Europe, comparing and contrasting patterns derived from both sets of information to better understand the species' demographic history, inferring recent colonization events, past expansions, and long-standing gene flow barriers.

Additionally, quantitative measurements of plumage coloration may allow for a simple but accurate method of identifying species, subspecies, and possibly populations. For example, Bleiweiss [69] exploited differences in UV coloration (as measured by a spectrometer) to distinguish between two morphologically similar and sympatric sibling species of tropical tanagers. Similarly, McKee and Erickson [70] were able to establish a rare occurrence of the Alder Flycatcher (Empidonax alnorum) in California by showing that the plumage coloration of the individual (as measured by a colorimeter) was outside the range of values for the morphologically similar Willow Flycatcher (E. traillii) which naturally occurs in California. Figuerola et al. [53] used a colorimeter to assess plumage coloration differences in wild populations of Blue Tits, finding differences among populations. They suggested that such techniques could be valuable for future studies of dispersal among populations. Norris et al. [71] exploited the variability of carotenoid pigments to help infer breeding populations in wintering American Redstarts (Setophaga ruticilla). They documented that the American Redstart displayed tail coloration from red to yellow, and that the color variation was best explained by regional habitat differences, and by extension populations, than by an individual's condition. Finally, Paxton et al. [72] found strong differences in plumage coloration of three western subspecies of the Willow Flycatcher. Such differ- 
ences could be exploited to identify subspecies during the wintering and migration periods more rapidly and without the technical expertise required for a more robust genetic approach. While such approaches hold the promise of a powerful tool for future research, the sole use of plumage coloration to identify distinct taxa should first be corroborated using other lines of evidence before being fully implemented in studies. In particular, geographically distinct populations may show differential coloration due to differences in environmental, not genetic, variation, which should be considered when interpreting results.

\section{CONCLUSION}

Plumage coloration is the product of several classes of pigments, micro-structural characteristics of the feather, or a combination of the two. Most coloration is believed to be a faithful expression of the genotype, but environmental variation appears to often influence expression to some degree. In particular, carotenoid pigments are not synthesized by birds and must be acquired from their diet, leading to the potential for significant variation in coloration dependent on condition of individuals. Other pigments, and structural colors, may have an environmental component in their expression. Therefore, studies that utilize plumage coloration should first assess the degree of variation found in the populations they choose to study. Electronic devices such as colorimeters and spectrometers provide rapid quantification of plumage coloration, which allows for replication among researchers and the ability to perform statistical analysis. Measurements of plumage coloration, if used carefully with an appreciation for the potential sources of non-genetic variation, can be another tool in a taxonomist's and ecologist's toolbox.

Reconstructing taxonomic relationships has often depended on evaluating how similar, or dissimilar, groups of taxa are to one another based on one or more lines of evidence. Such evolutionary reconstructions can never be definitively proved; rather, the weight of evidence is used to judge the strength of the inferred relationship, with multiple lines of independent evidence increasing the strength of the inferred relationships. To the extent that plumage coloration is a faithful expression of the genotype, measurements of coloration can provide a potentially rapid and less expensive method to distinguish among taxa. We are at the beginning, not the end, of understanding the complexity of plumage coloration as an expression of a bird's genome, and as our understanding of the mechanisms of expression evolve, the use of plumage coloration as an informative trait to understand evolutionary relationships likewise will evolve.

\section{ACKNOWLEDGEMENTS}

I thank Paul Keim, Kristina Paxton, Mark Sogge, Tad Theimer, and three anonymous reviewers for helpful comments on earlier drafts of this manuscript. Support for the author was provided by the U.S. Geological Survey and Northern Arizona University.

\section{REFERENCES}

[1] Mayr E. Animal species and evolution. Cambridge: Harvard University Press 1963.

[2] Zink RM, Rising JD, Mockford S, et al. Mitochondrial DNA variation, species limits, and rapid evolution of plumage coloration and size in the savannah sparrow. Condor 2005; 107: 21-8.
[3] Mundy NI. Genetic basis of color variation in wild birds. In: Hill GE, McGraw KJ, Eds. Bird Coloration: Mechanisms and Measurements. Cambridge: Harvard University Press 2006; vol. 1: pp. 469-506.

[4] Avise JC. Molecular markers, natural history and evolution. New York, NY: Chapman and Hall 1994.

[5] Mindell DP, Ed. Avian molecular evolution and systematics. New York: Academic Press 1997

[6] Nei M, Kumar S. Molecular Evolution and Phylogenetics. Oxford: Oxford University Press 2000

[7] Zink RM. The role of subspecies in obscuring avian biological diversity and misleading conservation policy. Proc R Soc Lond B 2004; 271: 561-4.

[8] Drovetski SV, Zink RM, Rohwer S, et al. Complex biogeographic history of a Holarctic passerine. Proc R Soc Lond B 2004; 271: 545-51.

[9] Moritz C. Applications of mitochondrial DNA analysis in conservation: a critical review. Mol Ecol 1994; 3: 401-11.

[10] Crandall KA, Bininda-Emonds ORP, Mace GM, Wayne RK Considering evolutionary processes in conservation biology. Trends Ecol Evol 2000; 15: 290-5.

[11] Mayr E. Principles of systematic zoology. New York: McGrawHill 1969.

[12] Haig SM, Beever EA, Chambers SM, et al. Taxonomic considerations in listing subspecies under the U.S. Endangered Species Act. Conserv Biol 2006; 20: 1584-94

[13] Johnson NK, Remsen JV, Cicero C. Refined colorimetery validates endangered species of the least tern. Condor 1998; 100: 18-26.

[14] Patten MA, Unitt P. Diagnosability versus mean difference of sage sparrow subspecies. Auk 2002; 119: 26-35.

[15] Fox HM, Vevers G. The nature of animal colors. New York: Macmillian 1960.

[16] Dyck J. Structural colors. Proc Int Ornithol Congr 1976; 16: 42637.

[17] McGraw KJ, Wakamatsu K, Ito S, et al. You can't judge a pigment by its color: carotenoid and melanin content of yellow and brown feathers in swallows, bluebirds, penguins, and domestic chickens. Condor 2004; 106: 390-5.

[18] McGraw KJ. Mechanics of melanin-based coloration. In: Hill GE, McGraw KJ, Eds. Bird Coloration: Mechanisms and Measurements. Cambridge: Harvard University Press 2006; vol. 1: pp. 243294.

[19] Niecke M, Rothlaender S, Roulin A. Why do melanin ornaments signal individual quality? Insights from metal element analysis of barn owl feathers. Oecologia 2003; 137: 153-8.

[20] Fargallo JA, Laaksonen T, Korpimaki E, Wakamatsu K. A melanin-based trait reflects environmental growth conditions of nestling male Eurasian kestrels. Evol Ecol 2007; 21: 157-71.

[21] Bortolotti GR, Blas J, Negro JJ, Tella JL. A complex plumage pattern as a honest social signal. Animal Behav 2006; 72: 423-30.

[22] McGraw KJ. Mechanics of Carotenoid-based coloration. In: Hill GE, McGraw KJ, Eds. Bird Coloration: Mechanisms and Measurements. Cambridge: Harvard University Press 2006; vol. 1: pp. $177-242$.

[23] Linville SU, Breitwisch R. Carotenoid availability and plumage coloration in a wild population of northern cardinals. Auk 1997; 114: 79-800

[24] Hadfield JD, Owens IPF. Strong environmental determination of a carotenoid-based plumage trait is not mediated by carotenoid availability. Evol Biol 2006; 19: 1104-14.

[25] Hill GE. Ornamental traits as indicators of environmental health Bioscience 1995; 45: 25-31.

[26] McGraw KJ. Mechanics of uncommon colors: pterins, porphyrins, and psittacofulvins. In: Hill GE, McGraw KJ, Eds. Bird Coloration: Mechanisms and Measurements, Cambridge: Harvard University Press 2006; vol. 1: pp. 354-398.

[27] Prum RO, Torres RH, Williamson S, Dyck J. Coherent light scattering by blue feather barbs. Nature 1998; 396: 28-9.

[28] Auber L. The distribution of structural colors and unusual pigments in the Class Aves. Ibis 1957; 99: 463-76.

[29] Masello JF, Lubjuhn T, Quillfeldt P. Is the structural and psittacofulvin-based coloration of wild burrowing parrots Cyanoliseus patagonus condition dependent? J Avian Biol 2008; 39: 653-62.

[30] Eaton MD. Human vision fails to distinguish widespread sexual dichromatism among sexual "monochromatic" birds. Proc Natl Acad Sci USA 2005; 102: 10942-6. 
[31] Prum RO. Anatomy, physics, and evolution of structural colors. In: Hill GE, McGraw KJ, Eds. Bird Coloration: Mechanisms and Measurements, Cambridge: Harvard University Press 2006; vol. 1: pp. 295-353.

[32] Jacot A, Kempenaers B. Effects of nestling condition on UV plumage traits in blue tits: an experimental approach. Behav Ecol 2007; 18: 34-40.

[33] Keyser AJ, Hill GE. Condition-dependent variation in the blueultraviolet coloration of a structurally based plumage ornament. Proc R Soc Lond B 1999; 266: 771-7.

[34] Buckley PA. Mendelian genes. In: Cooke F, Buckley PA, Eds. Avian Genetics, a population and ecological approach. New York: Academic Press 1987.

[35] Mundy NI. A window on the genetics of evolution: MC1R and plumage coloration in birds. Proc R Soc Lond B 2005; 272: 163340 .

[36] Theron E, Hawkins K, Bermingham E, Ricklefs R, Mundy NI. The molecular basis of an avian polymorphism in the wild: a point mutation in the melanocortin-1 receptor is perfectly associated with melanism in the Bananaquit (Coereba flaveola). Curr Biol 2001; 11: 550-7.

[37] Mundy NI, Badcock NS, Hart T, Scribner K, Janssen K, Nadeau NJ. Conserved genetic basis of a quantitative plumage trait involved in mate choice. Science 2004; 303: 1870-3.

[38] Cooke F, Rockwell RF, Lank DB. The Snow Geese of La Perouse Bay. Oxford: Oxford University Press 1995.

[39] Doucet S, Shawkey M, Rathburn M, Mays HM, Montgomerie R. Concordant evolution of plumage colour, feather microstructure, and a melanocortin receptor gene between mainland and island populations of a fairy-wren. Proc R Soc Lond B 2004; 271: 166370 .

[40] Price TD. Domesticated birds as a model for the genetics of speciation by sexual selection. Genetica 2002; 116: 311-27.

[41] Rohwer S, Wood C. Three hybrid zones between Hermit and townsend's warblers in Washington and Oregon. Auk 1998; 115: 284-310.

[42] Hill GE. House Finches are what they eat: a reply to Hudon. Auk 1994; 111: 221-5.

[43] McGraw KJ, Hill GE, Stradi R, Parker RS. The influence of carotenoid acquisition and utilization on the maintenance of speciestypical plumage pigmentation in male American Goldfinches (Carduelis tristis) and Northern Cardinals (Cardinalis cardenalis). Physiol Biochem Zool 2001; 74: 843-52.

[44] Hill GE. Energetic constraints on expression of carotenoid-based plumage coloration. J Avian Biol 2000; 31: 559-66.

[45] Hill GE, Inouye CY, Montgomerie R. Dietary carotenoids predict plumage coloration in wild house finches. Proc R Soc Lond B 2002; 269: 1119-24.

[46] Endler JA. Natural and sexual selection on color patterns in Poecilia reticulate. Evolution 1980; 34: 76-91.

[47] Olson VA, Owens IPF. Interspecific variation in the use of carotenoid-based coloration in birds: diet, life history, and phylogeny. J Evol Biol 2005; 18: 1534-46.

[48] McGraw KJ. Melanins, metals, and mate quality. Oikos 2003; 102: 402-6.

[49] Montgomerie R. Cosmetic and adventitious colors. In: Hill GE, McGraw KJ, Eds. Bird Coloration: Mechanisms and Measurements. Cambridge: Harvard University Press 2006; vol. 1: pp. 399427.

[50] Delhey K, Peters A, Johnsen A, Kempenaers B. Seasonal changes in blue tit crown color: do they signal individual quality? Behav Ecol 2006; 17: 790-8.
[51] Figuerola J, Senar JC. Seasonal changes in carotenoid and melaninbased plumage coloration in the great tit Parus major. Ibis 2005; 147: 797-802.

[52] Willoughby EJ, Murphy M, Gorton HL. Molt, plumage abrasion, and color change in Lawrence's Goldfinch. Wilson Bull 2002; 114: 380-92.

[53] Figuerola J, Senar JC, Pascual J. The use of a colorimeter in field studies of Blue tit Parus caeruleus coloration. Ardea 1999; 87: 269-75.

[54] McNett GD, Marchetti K. Ultraviolet degradation in carotenoid patches: live versus museum specimens of wood warblers (Parulidae). Auk 2005; 122: 793-802

[55] Inouye CY, Hill GE, Stradi RD, Montgomerie R. Carotenoid pigments in male house finch plumage in relation to age, subspecies, and ornamental coloration. Auk 2001; 118: 900-15.

[56] Cuthill IC, Partridge JC, Bennett ATD, Church SC, Hart NS, Hunt S. Ultraviolet vision in birds. Adv Study Behav 2000; 29: 159-214.

[57] Bennett ATD, Thery M. Avian color vision and coloration: multidisciplinary evolutionary biology. Am Nat 2007; 169: 1-6.

[58] Hart NS, Partridge JC, Cuthill IC, Bennett ATD. Visual pigments, oil droplets, ocular media and cone photoreceptor distribution in two species of passerine bird: the Blue Tit (Parus caeruleus) and the Blackbird (Turdus merula). J Comp Physiol 2000; 186: 375-87.

[59] Miller RS. The Munsell system of color notation. J Mammal 1958; 39: $278-86$

[60] Andersson S. Morphology of UV reflectance in a whistling-thrush: implications for the study of structural colour signaling in birds. J Avian Biol 1999; 30: 193-204.

[61] Schmitz-Ornes A. Using colour spectral data in studies of geographic variation and taxonomy of birds: examples with two hummingbird genera, Anthracothorax and Eulampis. J Ornithol 2006; 147: 495-503.

[62] Thompson BC, Schmidt ME, Calhoun SW, Morizot DC, Slack RD Subspecific status of least tern populations in Texas: North American implications. Wilson Bull 1992; 104: 244-62.

[63] Gomez D, Voisin J. Spectrometry validates subspeciation in the Kerguelen Tern Sterna virgata. Marine Ornithol 2002; 30: 19-24.

[64] Johnson NK, Jones RE. A new species of tody-tyrant (Tyrannidae: Poecilotriccus) from northern Peru. Auk 2001; 118: 334-41.

[65] Isler ML, Alonso JA, Isler PR, Valqui T, Begazo A, Whitney BM. Rediscovery of a cryptic species and description of a new subspecies in the Myrmeciza hemimelaena complex (Thamnophilidae) of the Neotropics. Auk 2002; 119: 362-78.

[66] Maley J, Winker K. The utility of juvenal plumage in diagnosing species limits: an example using buntings in the genus Plectrophenax. Auk 2007; 124: 907-15.

[67] Zink RM, Blackwell RC, Rojas-Soto O. Species limits in the Le Conte's Thrasher. Condor 1997; 99: 1328

[68] Johnsen A, Andersson S, Fernandez JG, et al. Molecular and phenotypic divergence in the bluethroat (Luscinia svecica) subspecies complex. Mol Ecol 2006; 15: 4033-47.

[69] Bleiweiss R. Ultraviolet plumage reflectance distinguishes sibling bird species. Proc Natl Acad Sci USA 2004; 101: 16561-4.

[70] McKee T, Erickson RA. Report of the California Bird Records Committee: 2000 records. West Birds 2002; 33: 175-201.

[71] Norris DR, Marra PP, Kyser TK, Ratcliffe LM, Montgomerie R. Continent-wide variation in feather colour of a migratory songbird in relation to body condition and moulting locality. Biol Lett 2006; 3: $16-19$.

[72] Paxton EH, Causey CF, Koronkiewicz TJ, et al. Assessing variation of plumage coloration within the Willow Flycatcher: a preliminary analysis. U.S. Geological Survey Report 2005. 